\title{
Electrochemical Characterization of Low-Temperature Direct Ethanol Fuel Cells using Direct and Alternate Current Methods
}

\author{
Paweł Wnuk $^{1} \cdot$ Rafał Jurczakowski $^{1} \cdot$ Adam Lewera $^{1}$ (D) \\ Published online: 26 October 2019 \\ (C) The Author(s) 2019
}

\begin{abstract}
Here, we report for the first time the results of systematic characterization of a low-temperature polymer electrolyte membrane direct ethanol fuel cell using DC and AC electrochemical methods. Model catalysts (carbon supported Pt nanoparticles) painted on carbon paper are used as anode and cathode. Influence of physical parameters, such as cell temperature, current density, and ethanol concentration, and anode fuel flow rate on overall cell impedance is studied. Analysis of the obtained impedance spectra in connection with DC measurements allows us to comment on cell properties and to separate different contributions to the overall cell polarization. Our results suggest that the cell impedance is dominated by anode faradaic impedance, with a small or negligible contribution from cathode faradaic impedance. The anode impedance depends strongly on current density and cell temperature, but is not significantly influenced by ethanol concentration. Presence of anode mass-transfer impedance, even when ethanol was fed to the cell in high excess, is confirmed. Based on the results, we conclude that changes in ethanol electrooxidation mechanism might manifest themselves on the impedance spectra in the low-frequency inductive loop. Nonetheless, further studies involving equivalent circuit modelling are needed to determine the exact influence of the cell parameters on the anode kinetics.
\end{abstract}

Keywords Ethanol $\cdot$ Electrocatalysis $\cdot$ Platinum $\cdot$ Fuel cell $\cdot$ Electrochemical impedance spectroscopy

\section{Introduction}

Low-temperature polymer electrolyte membrane fuel cells (PEM FCs) are considered promising energy sources for sustainable and environment-friendly energy conversion [1]. Among various PEMs, direct methanol (DMEFCs), formic acid (DFAFCs), dimethyl ether (DDMEFC), and ethanol fuel cells (DEFCs) have many potential advantages, such as high theoretical energy density of the fuel, high theoretical thermodynamic efficiency of fuel oxidation, and ease of storage and transportation, and in case of ethanol, the ease of production and carbon-neutrality [2-7].

Electronic supplementary material The online version of this article (https://doi.org/10.1007/s12678-019-00559-w) contains supplementary material, which is available to authorized users.

Adam Lewera

alewera@chem.uw.edu.pl

1 Department of Chemistry, Biological and Chemical Research Centre, University of Warsaw, ul. Żwirki i Wigury 101,

02-089 Warsaw, Poland
The practical efficiencies of fuel cells with ethanol as the anode fuel are still low in comparison with other investigated fuels, such as hydrogen, methanol, or ethylene glycol [2], which is mainly caused by (I) poisoning of commonly used platinum-based electrodes by intermediate products of ethanol oxidation, resulting in poor ethanol electro-oxidation kinetics $[3,8,9]$, (II) ethanol cross-over phenomenon [8, 10, 11], and (III) low durability of the polymer electrolyte membranes at high temperatures [12-14]. Additionally, the complex mechanism of ethanol oxidation reaction (EOR) leads to three main products: acetaldehyde, acetic acid, and carbon dioxide, which is accompanied by release of 2, 4, and 12 electrons per one ethanol molecule respectively [15]. Therefore, only high carbon dioxide yields allow for obtaining good practical efficiencies of DEFC.

The highest reported power densities of low-temperature PEM DEFC reach up to ca. $100 \mathrm{~mW} \mathrm{~cm}^{-2}$, but more importantly, no significant improvements in terms of power have been made in recent years $[2,4,16]$. A possible reason might be the fact that high activity of the state-of-the-art anodes, such as $\mathrm{PtSn}_{x}$ and $\mathrm{PtRu}_{x}$ alloys, is based on the so-called bi-functional mechanism, which facilitates acetic acid as the main product [17-20]. Acetic acid is a "dead-end" product of ethanol oxidation, i.e., it cannot 
be further oxidized under typical cell operating conditions [21, 22]. As a result, the maximum practical efficiency is severely reduced to about one-third of the theoretical value. Moreover, acetic acid has an inhibiting effect on ethanol oxidation, which could be a significant problem in terms of incorporating fuel circulation systems [22]. Possible improvements of cell power and efficiency could be achieved by facilitating full oxidation route to carbon dioxide. In recent years, $\mathrm{PtRh}_{x} \mathrm{Sn}_{y}$ and $\mathrm{PtRh}_{x}\left(\mathrm{SnO}_{2}\right)_{y}$ were considered promising candidates for anode catalysts. It was reported in ex situ studies by several groups that these catalysts may show high activity towards ethanol oxidation and it was proposed that it may be a result of facilitated carbon dioxide formation, based on IR spectroscopy measurements [23-32]. However, in situ experiments showed that power densities obtained for fuel cells with such catalysts (max. $80 \mathrm{~mW}$ $\mathrm{cm}^{-2}$ at $100{ }^{\circ} \mathrm{C}$ ) were not higher than the state-of-the-art values and no improvements in $\mathrm{CO}_{2}$ yields were confirmed [33-36]. In our previous work, we reported that, under certain conditions, carbon-supported platinum catalysts may show exceptionally high selectivity towards $\mathrm{CO}_{2}$ formation, but only when current density is low [37]. Nevertheless, platinum is known to have the highest activity towards ethanol oxidation among pure metals, and is considered a necessary component of the electrodes for DEFC. Better understanding of factors influencing ethanol oxidation reaction on model system, such as $\mathrm{Pt} / \mathrm{C}$, allows to develop new, more active DEFC catalysts. This is the reason we decided to devote our manuscript to investigation of Pt used as a model anode and cathode catalyst.

In recent years, electrochemical impedance spectroscopy (EIS) has proven useful for in situ investigation of PEM fuel cells fed with hydrogen, methanol, or formic acid [38-40]. However, literature reports on application of this method for PEM DEFC studies are scarce. Ekdharmasuit et al. investigated influence of ethanol concentration on anode impedance [41], while Zignani et al. used EIS for assessment of cell degradation [42]. In both works, only fuel cells with $\mathrm{PtSn}_{x}$ as anode catalysts were studied. Moreno-Jiménez et al. used impedance spectroscopy to examine the influence of construction parameters, such as catalyst layer location and air supply mode, in open-cathode DEFC [43]. In all the abovementioned articles, the impedance spectra were registered in a relatively narrow range of perturbation frequency (down to $50-100 \mathrm{mHz}$ ) and only at a single cell voltage or current density. In this work, we present results of systematic electrochemical investigation of direct ethanol fuel cells with carbon-supported platinum electrodes using DC (galvanostatic polarization) and AC (electrochemical impedance spectroscopy) methods and assess the influence of basic working parameters (ethanol concentration, anode flow rate, temperature, current density) on the cell properties. The connection of those two complementary techniques might be a useful tool for understanding of the underlying phenomena occurring in a direct ethanol fuel cell.

\section{Experimental}

All chemicals used were of analytical grade and were used without further purification. Catalyst inks were prepared using commercial $\mathrm{Pt} / \mathrm{C}$ catalysts with $20 \%$ (BASF) and $40 \%$ (ETEK) platinum content for anode and cathode respectively. TEM images of the material used are presented in Fig. S3 and S4 (Supplementary Information). Five percent Nafion ${ }^{\circledR}$ solution (DuPont) and isopropanol were added to the preweighted catalyst powders. The Nafion $®$ amount was adjusted so that its content in the dry catalyst mass was ca. $32 \%$. The obtained suspensions were stirred for at least $1 \mathrm{~h}$. The anode and the cathode were obtained by painting the catalyst suspension on carbon paper squares (Torray Inc.) with geometric area of $10 \mathrm{~cm}^{-2}$. Geometric area was used to calculate cell current and power density. The obtained platinum loading was about $1.0 \mathrm{mg} \mathrm{cm}^{-2}$ for both electrodes. The membrane used in the cell (the electrolyte) was Nafion ${ }^{\circledR} 117$ heated in $0.5 \mathrm{M} \mathrm{H}_{2} \mathrm{SO}_{4}$ solution at $80^{\circ} \mathrm{C}$ for $1 \mathrm{~h}$ and rinsed with deionized water prior to using. Fuel cell hardware (Fuel Cell Inc.) consisting of graphite plates with single serpentine flow pattern was used. The cell was assembled using the electrodes prepared as described above, Nafion ${ }^{\circledR}$ membrane and fiberglass reinforced Teflon ${ }^{\circledR}$ gaskets. The cathode was fed with ultrapure oxygen (N6.0 by Air Products Inc.) at a fixed flow rate of $75 \mathrm{ml} \mathrm{min}^{-1}$ and ambient pressure, and the anode was supplied with ethanol solution using a peristaltic pump. The varied parameters were cell temperature, ethanol concentration, and ethanol flow rate.

The electrochemical measurements, control of cell parameters, such as temperature and oxygen flow rate, and data acquisition were carried out using 850e Fuel Cell Test System from Scribner Associates Inc. For each set of investigated cell parameters, experimental procedure was the same. First, the cell was conditioned for $1 \mathrm{~h}$ at a constant current load of $10 \mathrm{~mA} \mathrm{~cm}{ }^{-2}$, followed by several hours of open-circuit operation until steady state voltage was reached. Next, polarization curves were registered in galvanodynamic conditions with a current scan rate of $2 \mathrm{~mA} \mathrm{~min}{ }^{-1}$ Afterwards, a series of experiments at different current loads were conducted consisting of constant current operation for $5 \mathrm{~h}$. A comparison of voltage/current data points obtained in galvanodynamic and galvanostatic (see below) conditions is shown in Fig. S6 and Tab. S1. As the difference is small, it can be concluded that the obtained polarization curves represent quasi-stationary conditions, with small deviations from real steady-state values.

The galvanostatic experiments were followed directly by electrochemical impedance measurement in galvanostatic mode. A sinusoidal current perturbation was applied with amplitude upper limit set to no more than $10 \%$ of a given current load and frequency in the range of $3 \mathrm{kHz}-1 \mathrm{mHz}$ with 20 points 
registered per decade. Validity of the obtained spectra was confirmed by Kramers-Kronig transformations (see Supplementary Information, Fig. S2). In the experimental course, lasting ca. 6 weeks, the maximum power density decreased by no more than 15\% (see Supplementary Information, Fig. S5). Taking into account that each impedance measurement lasted ca. 15-20 h, we assume that output power decrease during a single impedance measurement was no more than $0.3 \%$. Therefore, we conclude that cell degradation has no significant influence on conclusions presented here.

\section{Results and Discussion}

\section{Influence of ethanol concentration-DC measurements}

Polarization curves for DEFC with Pt anode and cathode (see "Experimental" section) and the corresponding polarization resistance dependence on current density registered for different ethanol concentrations are presented in Fig. 1a and b, respectively. The polarization resistance plots were obtained by means of calculating the first derivative of cell voltage with respect to cell current using the obtained polarization curves. The open-circuit voltages $(\mathrm{OCV})$ observable on the polarization curves (points at $I=0 \mathrm{~mA} \mathrm{~cm}{ }^{-2}$ ) for $0.1 \mathrm{M}, 0.2 \mathrm{M}$, and $0.5 \mathrm{M}$ ethanol are 510,467 , and $424 \mathrm{mV}$ respectively. Those $\mathrm{OCV}$ values are far from the theoretical open-circuit voltage of DEFC under standard conditions (1.14 V [2]) due to high anode and cathode overpotential. As it can be also seen, OCV decreases as ethanol concentration increases, which already has been attributed to ethanol diffusion through Nafion ${ }^{\circledR}$ membrane and its parasitic oxidation at the cathode, which lowers the cathode potential and in turn the cell voltage $[8$, 10]. When current density increases, voltage firstly decreases exponentially, which can be attributed to voltage losses related to overcoming activation barrier for the electrode reactions (activation voltage losses) [1, 44], followed by a further rapid decrease, observable on Fig. 1a for $0.1 \mathrm{M}$ and $0.2 \mathrm{M}$ concentrations at high current densities $\left(I>10 \mathrm{~mA} \mathrm{~cm}^{-2}\right.$ for $0.1 \mathrm{M}$ and $I>20 \mathrm{~mA} \mathrm{~cm}^{-2}$ for $0.2 \mathrm{M}$ ), which is indicative of ethanol shortage at the anode surface (mass-transfer resistance).

Using polarization resistance plots, presented in Fig. 1b, it can be observed that the polarization resistance values are comparable between all three studied ethanol concentrations in the current density range from 0 to $10 \mathrm{~mA} \mathrm{~cm}^{-2}$, indicating similar activation voltage losses. It can be assumed that the total cell polarization resistance consists mainly of sum of anode and cathode resistances. Thus, the fact that ethanol concentration does not influence the total polarization resistance indicates that either both anode and cathode polarization resistances do not change with the concentration, or (less likely) the changes in resistance of one of the electrodes are
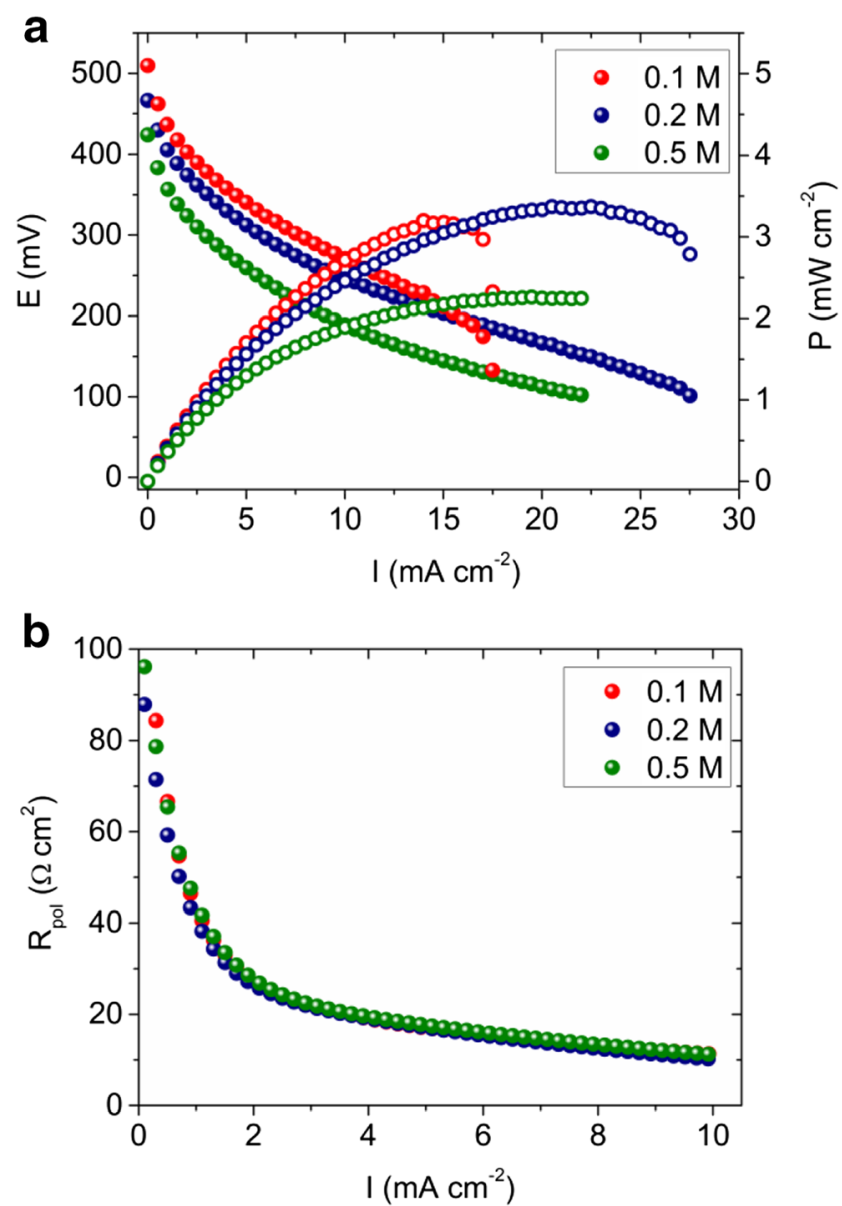

Fig. 1 a) Current-voltage (filled circles) and current-power (empty circles) characteristics. b) Polarization resistance as a function of current density for DEFC with Pt:Pt anode:cathode (see text for details) fed with ethanol solutions $(0.1,0.2$ and $0.5 \mathrm{M})$ and oxygen as oxidizer. Conditions:

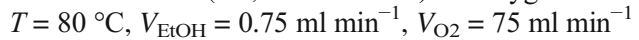

compensated by changes in resistance of the other electrode. One might expect that for higher ethanol concentrations, the polarization resistance absolute value of the cathode increases, due to the well-known fact that intermediate products of parasitic oxidation of ethanol at the cathode may poison it [45-47]. In fact, for $0.5 \mathrm{M}$ ethanol solution, the rate of crossover and oxidation of ethanol at the cathode is much higher than for $0.1 \mathrm{M}$, which is indicated by $86 \mathrm{mV}$ decrease in opencircuit voltage. However, given sluggish ethanol electrooxidation kinetics on platinum, (obviously resulting in very high anode resistance), the changes in the cathode resistance may be negligible in comparison with the total cell resistance. Given this assumption, the anode resistance also should not significantly change with ethanol concentration, resulting in comparable polarization resistance values for different concentrations. This can be rationalized due to the fact that at low current densities (meaning low anode potentials), the surface of anode catalyst might be almost completely poisoned for all three concentrations studied, considering exceptionally high affinity of platinum to ethanol oxidation intermediate 
products, such as carbon monoxide. As a result, current can be drawn from the cell only by means of platinum de-poisoning occurring when the anode potential increases, which is independent of ethanol concentration. This agrees well with ex situ studies of ethanol electro-oxidation [21, 22, 48]. As mentioned before, the rapid voltage decrease observable on the polarization curves in Fig. 1a at high current densities can be possibly ascribed to ethanol mass-transfer resistance. It is supported by the fact that the current density for which the rapid decrease in voltage occurs strongly depends on ethanol concentration. In particular for $0.1 \mathrm{M} \mathrm{EtOH}$, this feature is evident at the lowest current density $\left(I>10 \mathrm{~mA} \mathrm{~cm}^{-2}\right)$, for $0.2 \mathrm{M}$, it is observed at a higher current density $\left(I>20 \mathrm{~mA} \mathrm{~cm}^{-2}\right)$ whereas for $0.5 \mathrm{M}$, it is not observable at all. The oxygen flow rate used in the experiments $\left(V_{\mathrm{O} 2}=75 \mathrm{ml} \mathrm{min}{ }^{-1}\right)$ provided a significant excess of oxygen given the maximum observed current density values; hence, a contribution from oxygen mass-transfer resistance can be excluded. Therefore, we attribute the observed decrease in voltage at high current to depletion of ethanol at electrode surface. It is worth to compare here the current densities measured to the theoretical values of Faradaic current for different concentrations of ethanol, and assuming different EOR products, due to the fact that the Faradaic current depends strongly on the type of products formed during ethanol oxidation - partial oxidation of ethanol results in a lower number of electrons obtained per ethanol molecule (2 and 4 for oxidation to acetaldehyde and acetic acid respectively) than the 12 electrons possible to obtain, when $\mathrm{CO}_{2}$ is the only product. In Table 1, we summarized the calculated theoretical maximum values of current density that can be drawn for two extreme cases - when acetaldehyde is the only product $\left(I_{\mathrm{AAL}, \mathrm{MAX}}\right)$, and when carbon dioxide is the only product $\left(I_{\mathrm{CO} 2, \mathrm{MAX}}\right)$ for a constant ethanol flow: $V_{\mathrm{EtOH}}=0.75 \mathrm{ml}$ $\mathrm{min}^{-1}$. Ratio of $I_{\mathrm{AAL}, \mathrm{MAX}}$ or $I_{\mathrm{CO} 2, \mathrm{MAX}}$ to the experimental current densities (see Fig. 1a) obtained at $100 \mathrm{mV}$ cell voltage in DC measurements $\left(I_{100 \mathrm{mV}}\right)$ has also been calculated $\left(r_{\mathrm{AAL}}\right.$ and $r_{\mathrm{CO} 2}$, respectively) and are given in Table 1 .

Assuming the complete oxidation of ethanol (to carbon dioxide; with 12 electrons released per one ethanol molecule), the

Table 1 Experimental current densities $\left(I_{100 \mathrm{mV}}\right)$ at cell voltage $U=$ $100 \mathrm{mV}$ and $T=80^{\circ} \mathrm{C}$, theoretical maximum current densities $\left(I_{\mathrm{AAL}}\right.$ and $\left.I_{\mathrm{CO} 2}\right)$ and the corresponding ratio of the theoretical current densities to the experimental current densities at $100 \mathrm{mV}\left(r_{\mathrm{AAL}}, r_{\mathrm{CO} 2}\right)$ for two extreme cases of ethanol electro-oxidation: $I_{\mathrm{AAL}}, r_{\mathrm{AAL}}$-acetaldehyde is the only product and $I_{\mathrm{CO} 2}, r_{\mathrm{CO} 2}$ - carbon dioxide is the only product

\begin{tabular}{llll}
\hline Concentration $\left(\mathrm{mol} \mathrm{dm}^{-3}\right)$ & 0.1 & 0.2 & 0.5 \\
\hline$I_{100 \mathrm{mV}}\left(\mathrm{mA} \mathrm{cm}^{-2}\right)$ & 17.5 & 27.6 & 22.2 \\
$I_{\mathrm{AAL}}\left(\mathrm{mA} \mathrm{cm}^{-2}\right)$ & 48 & 96 & 242 \\
$r_{\mathrm{AAL}}$ & 2.7 & 3.5 & 10.9 \\
$I_{\mathrm{CO} 2}\left(\mathrm{~mA} \mathrm{~cm}^{-2}\right)$ & 288 & 576 & 1452 \\
$r_{\mathrm{CO} 2}$ & 16.5 & 20.9 & 65.4 \\
\hline
\end{tabular}

calculated ratio of theoretical and experimental current densities is very high for all three concentrations considered (16.5, 20.9 , and 65.4 for $0.1,0.2$, and $0.5 \mathrm{M}$ respectively). With $0.5 \mathrm{M}$ ethanol solution fed to the anode, the maximum theoretical current, assuming that acetaldehyde is the only product, is still ca. 10 times higher than the experimental current registered at $100 \mathrm{mV}$. The above calculations suggest that ethanol is in high excess, when $0.5 \mathrm{M}$ concentration is used, regardless of the distribution of ethanol oxidation products, which explains the absence of mass-transfer resistance on the polarization curve for this concentration (see Fig. 1a). On the contrary for $0.1 \mathrm{M}$ and $0.2 \mathrm{M}$, a rapid voltage decrease at high current densities was observed (Fig. 1a), and the $r_{\mathrm{AAL}}$ values are much smaller; equal to 2.7 and 3.5 respectively. Even though the calculated $r_{\mathrm{AAL}}$ values for 0.1 and $0.2 \mathrm{M} \mathrm{EtOH}$ are relatively small, the cell is still being fed with ethanol in excess. The observable mass-transfer resistance might thus be linked to formation of concentration gradients along the flow channels or across the diffusion layer (the carbon support of the catalyst and the catalyst layer), which will be more pronounced at lower ethanol concentration. In general, low selectivity towards full oxidation to $\mathrm{CO}_{2}$ may be an important cause of mass-transfer resistance at high current densities. In fact, in situ studies of anode product distribution for DEFC with platinum electrodes have shown that acetaldehyde is the main product in a wide range of cell operating conditions [17, 34].

The mass-transfer resistance can be likewise related to other reasons causing decrease of ethanol concentration at anode surface, such as its diffusion through Nafion ${ }^{\circledR}$ membrane or currentless oxidation by oxygen permeating to the anode compartment; the latter phenomenon has been shown in our previous work [49]. It is worth mentioning that occurrence of anode masstransfer resistance, even when fuel was in excess, has been previously reported for direct methanol fuel cells [50-52], which shows many similarities to direct ethanol fuel cells.

It is noteworthy that for some PEM fuel cells, mainly $\mathrm{H}_{2} /$ $\mathrm{O}_{2}$ systems, also a third region on polarization curves is recognizable, i.e., a current density range where voltage losses are a linear function of current density and this region is dominated by ohmic losses $[44,53]$. In Fig. 1a, this part of the curve is not easily distinguishable. We suppose that for DEFC, even at relatively high current densities, majority of the losses still come from the activation voltage losses, similarly to direct methanol fuel cells [54]. This aspect was studied using impedance spectroscopy and will be described in more details in the following sections. As can be seen from the above considerations, the individual contributions to the overall cell voltage losses cannot be easily extracted from polarization curves of the whole cell. Other approaches are necessary, such as using electrochemical impedance spectroscopy which allows to separate processes characterized by different time constants. 


\section{Influence of Ethanol Concentration-Impedance Spectra}

While DC polarization curves and dependency of polarization resistance on current density deliver information about the total cell voltage losses for a given current density load, electrochemical impedance spectroscopy may allow for determination of contributions from different processes on overall cell performance. Using perturbation of alternating electric signal over a wide range of frequency, phenomena characterized by different relaxation time constants can be separated from the system's response. Therefore, DC and AC techniques are complementary and when used together they allow for more detailed characterization of a working DEFC. The impedance spectra within this work were measured in galvanostatic mode. This type of measurement has the following advantages: (a) the cell voltage contains a relevant contribution from cross-over phenomenon that reduces the cathode potential, but does not affect the anode polarization, which is of great interest. Therefore, spectra obtained in potentiostatic conditions for the same cell voltage, but different ethanol concentrations are not directly comparable. (b) The mass-transfer resistance depends strongly on the current drawn from the cell.

In order to obtain reliable impedance spectra, conditions of stationarity and linearity must be fulfilled. Desilets et al. reported that surface of a platinum electrode immersed in a $1 \mathrm{M}$ ethanol solution undergoes continuous evolution due to poisoning by reaction intermediates (products of ethanol dissociative adsorption and partial oxidation), so that steady-state conditions are not acquired even after $30 \mathrm{~h}$, as evident from constantly evolving impedance spectra [55]. As a comparison, in our work, a stationary state, indicated by no changes of the cell voltage (and as a result - no changes in impedance spectra over time), was been reached after ca. 4-5 $\mathrm{h}$ in the open-circuit conditions and after 1$3 \mathrm{~h}$ in the constant current experiments preceding the impedance measurements (see Supplementary Information, Fig. S1). We suppose that the fact of reaching stationary state in the fuel cell is facilitated by the forced constant flow of reactants. In addition, oxygen may oxidize surface poisons [49], present at the cathode, due to ethanol permeation from anode side, and similarly depoisoning of the anode is also facilitated by oxygen permeating from the cathode side. Those processes in turn allow for a dynamic equilibrium in the poisoning processes to establish. Due to the steady-state conditions and no evolution of electrodes over time, the impedance spectra in this work could be registered in a wide range of perturbation frequency (down to $1 \mathrm{mHz}$ ). Such low frequencies cannot be applied in ex situ experiments, which are limited to potentiodynamic conditions [55]. Linear response upon the imposed AC signals was assured by adjusting amplitudes of the perturbations, so that no deviation from linear behavior is observed on the polarization curves in the perturbation range around a given current density load.
Figure 2 shows evolution of the obtained impedance spectra for two ethanol concentrations $-0.1 \mathrm{M}$ and $0.5 \mathrm{M}$ as a function of current density. The intercepts with real axis at high frequency in Nyquist plot in Fig. 2a represent ohmic resistance. It can be easily noticed that its values are at least an order of magnitude lower than the overall cell impedance value for all of the presented spectra. This confirms that on the polarization curves in Fig. 1a, no region dominated by ohmic losses exists. Another common feature of all the spectra is the presence of a high-frequency arc (arc I in Fig. 2) with a phase angle maximum at around $1-10 \mathrm{~Hz}$ and a mid-frequency arc (arc II in Fig. 2) with a phase angle maximum at around 0.05$0.5 \mathrm{~Hz}$ ). The most significant change observed upon increasing current density for both $0.1 \mathrm{M}$ and $0.5 \mathrm{M}$ ethanol solution is that the diameter of the mid-frequency arc (arc II in Fig. 2) decreases. Taking into account that ethanol electro-oxidation kinetics at the anode limit the overall cell performance, this arc is mostly influenced by the anode faradaic impedance. The high-frequency arc (arc I in Fig. 2) corresponds to a process characterized by a lower relaxation time constant. Its size also shrinks with increasing current, but the change is much smaller than for the mid-frequency arc. Additionally, the decrease in size of this arc with increasing current density is much more pronounced for $0.1 \mathrm{M}$ ethanol than for $0.5 \mathrm{M}$. To better understand this behavior, the above observations will be discussed together with other data, later in this work.

In the low-frequency part of the spectra in Fig. 2 (ca. 1-5 $\mathrm{mHz}$ ), an inductive behavior is evident for higher current densities, and less noticeable for low current densities. Expanded view of inductive "loops" visible on the spectra for $0.5 \mathrm{M}$ ethanol solution is shown in the inset of Fig. 2a; A and B denote the first and the second inductive loop region, respectively. Inductive features can manifest on the spectra when faradaic impedance of the system studied depends on electrode potential and on one or more potential-dependent state variables [56, 57]. In case of DEFC, the state variables can be coverages of electrode surface with different reaction intermediates. In such case, inductive behavior would be indicative of slow processes of adsorption and desorption of reaction intermediates, which are involved in the ethanol electro-oxidation mechanism $[3,21,58]$. For higher current density values, a positive phase angle can be already observed on the Bode plots in Fig. $2 \mathrm{~b}$ at higher frequencies, meaning that the inductive phenomena are characterized by lower relaxation time constants.

For $0.1 \mathrm{M}$ ethanol solution at current densities greater than, or equal to, $10 \mathrm{~mA} \mathrm{~cm}{ }^{-2}$, an additional feature (deformed semi-circle, marked as III in Fig. 2a) on impedance spectra can be observed. This feature is even more pronounced for higher current density $\left.(15 \mathrm{~mA} \mathrm{~cm})^{-2}\right)$ at this ethanol concentration, but is not present at all for $0.5 \mathrm{M}$ ethanol even at current densities as high as $20 \mathrm{~mA} \mathrm{~cm}$. This observation is consistent with the rapid voltage decrease observable in the voltage-current curve for $0.1 \mathrm{M}$ 

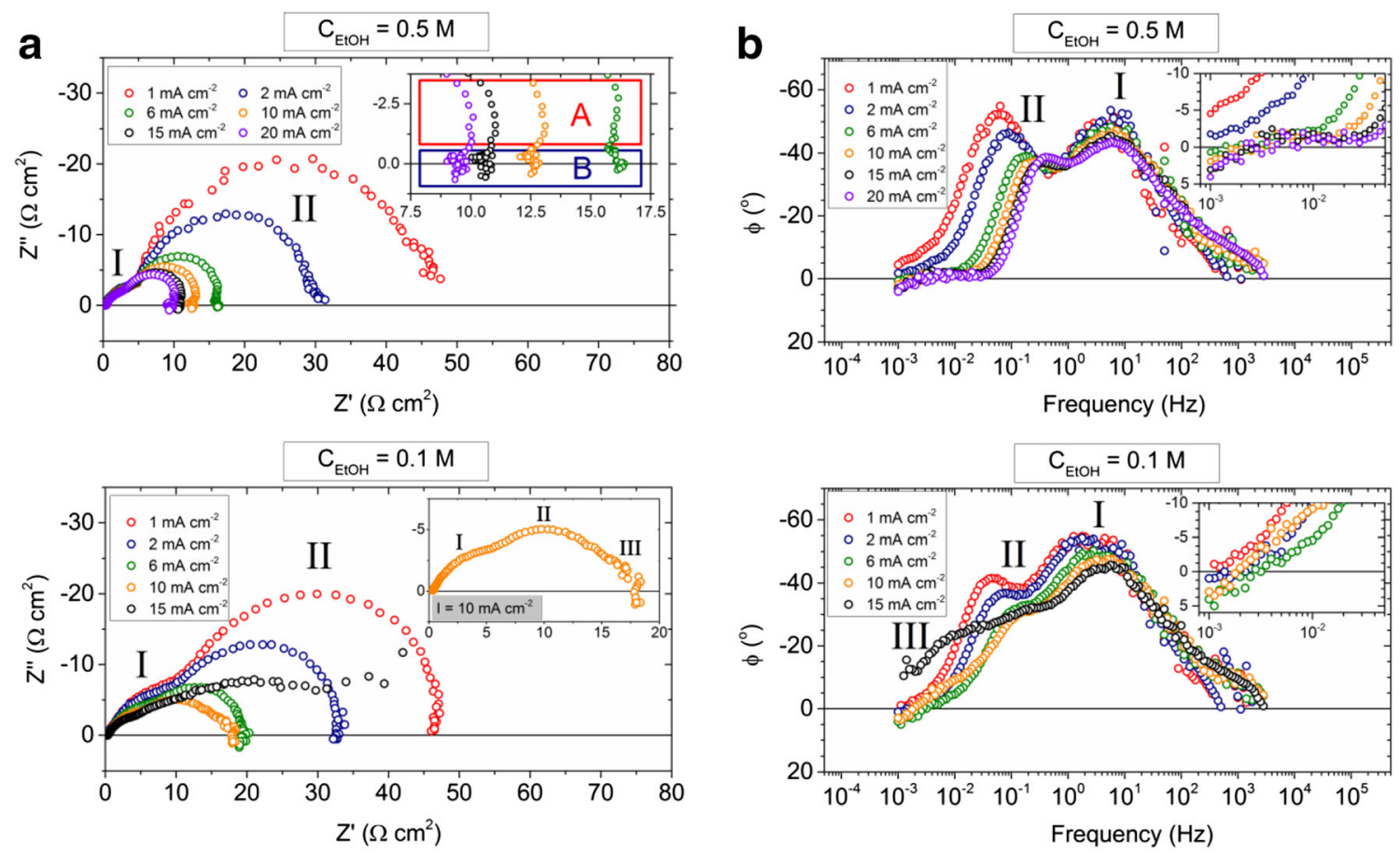

Fig. 2 Impedance spectra of DEFC with Pt:Pt anode:cathode (see text for details) fed with ethanol solutions $(0.1 \mathrm{M}$ and $0.5 \mathrm{M})$ and oxygen as oxidizer at different current densities. a) Nyquist plots and b) Bode

ethanol at high current densities (Fig. 1a, red curve), and also with the fact that for $0.5 \mathrm{M}$ ethanol voltage does not decrease significantly when current density is increased (Fig. 1a, green curve). This suggests that mass-transfer impedance, corresponding to diffusion of ethanol to the active sites of the anode catalyst due to depletion of ethanol at electrode surface, has an impact on the overall impedance. Obviously, mass transfer is not the only factor influencing the low-frequency region of the spectra, because if the mass transfer would be the main limiting factor, a pure Warburg-type behavior would be expected, characterized by a line with unity slope on the Nyquist plot for semi-infinite diffusion, or a line with unity slope followed by an arc terminated at real axis in case of finite-length diffusion (when transmissive boundary condition is fulfilled, which is usually assumed for fuel cell electrodes) [59, 60].

In order to gain a deeper understanding of the data shown in Fig. 2, we compared Bode and Nyquist plots for different ethanol concentrations, at a given current density in Fig. 3. It can be seen from the Nyquist plots in Fig. 3a that for different ethanol concentrations, no significant changes in the size of the mid-frequency arc (arc II in Fig. 3a) occur at three presented current densities $\left(2,6\right.$, and $\left.15 \mathrm{~mA} \mathrm{~cm}^{-2}\right)$. In the Bode plots in Fig. $3 \mathrm{~b}$ for a given current density, the maximum phase angle corresponding to this arc (arc II in Fig. 3b) appears at almost identical frequency at each concentration, indicative of similar relaxation time constants. These observations suggest

plots. Conditions: $T=80{ }^{\circ} \mathrm{C}, V_{\mathrm{EtOH}}=0.75 \mathrm{ml} \mathrm{min}{ }^{-1}, V_{\mathrm{O} 2}=75 \mathrm{ml}$ $\mathrm{min}^{-1}$. Insets contain the expanded view of selected spectra, presented here for clarity

that the anode faradaic impedance is practically independent of the concentration used and is in good agreement with the conclusions from the analysis of polarization resistance values in Fig. $1 b$.

The main differences between the spectra at low current densities $\left(I=2\right.$ and $\left.6 \mathrm{~mA} \mathrm{~cm}{ }^{-2}\right)$ are apparent in the high-frequency arc (arc I in Fig. 3). This arc is characterized by a lower time constant, which corresponds to a faster process, and due to the fact that the EOR is rate limiting, this would suggest that this arc corresponds to cathode faradaic impedance. However if it would correspond only to the cathode faradaic impedance, one would expect an increase in the size of this arc upon increasing ethanol concentration, because of the detrimental effect of ethanol cross-over phenomenon on cathode performance. Against this hypothesis, changes occur in the opposite direction. It cannot be excluded that also non-faradaic processes, connected with porous character of the electrodes used, contribute to impedance observed in the high frequency region [61]. Moreover, a distinctive feature is that the size of the arc $I$ in Fig. 3 a and its corresponding relaxation time constant at high current density $\left(I=15 \mathrm{~mA} \mathrm{~cm}^{-2}\right)$ become virtually the same for $0.1,0.2$, and $0.5 \mathrm{M}$ ethanol solutions. Based on the above data the exact origin of the high-frequency arc remains unclear.

Another noteworthy feature is that the observed shape of the inductive loops present at low frequencies in the 

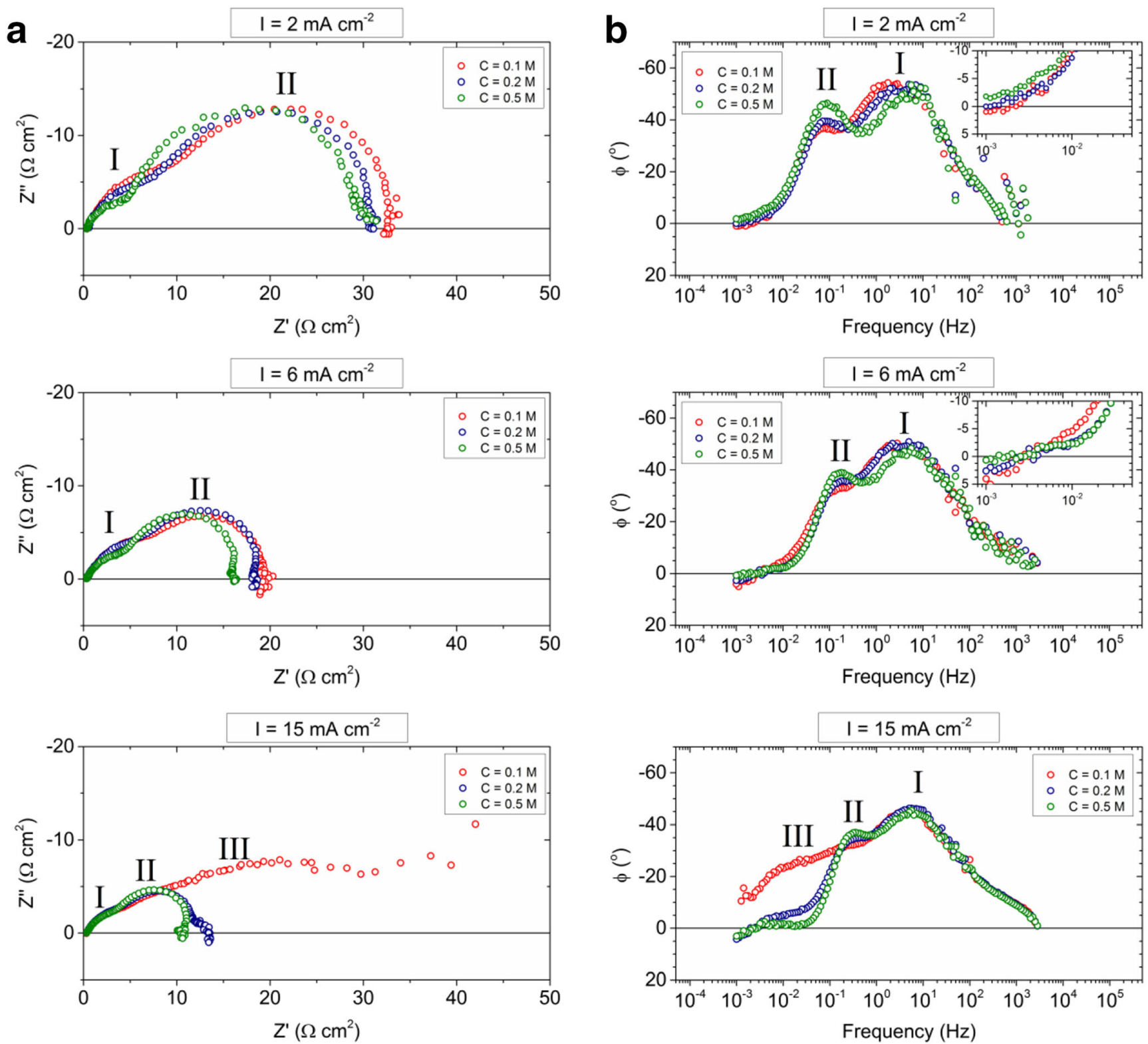

Fig. 3 Impedance spectra of DEFC with Pt:Pt anode:cathode (see text for details) fed with ethanol solutions $(0.1,0.2$, and $0.5 \mathrm{M})$ and oxygen as oxidizer. a) Nyquist plots and b) Bode plots. Conditions: $T=80^{\circ} \mathrm{C}, V_{\mathrm{EtOH}}$

Nyquist and Bode plots (Fig. 3a and b) is different, depending on the ethanol concentration used. Considering complicated ethanol electro-oxidation mechanism with three main products, several adsorbed intermediate species might be accountable for the inductive behavior and it is expected that ethanol concentration would influence the type and amount of intermediates [48]. The inductive portion of the spectra might be also connected with reactions at the cathode. It has been reported in the literature that cathodes of direct methanol fuel cells, poisoned by intermediate products of parasitic methanol oxidation, exhibit inductive features at low perturbation frequencies, which vary with the methanol concentration $[38,62$,

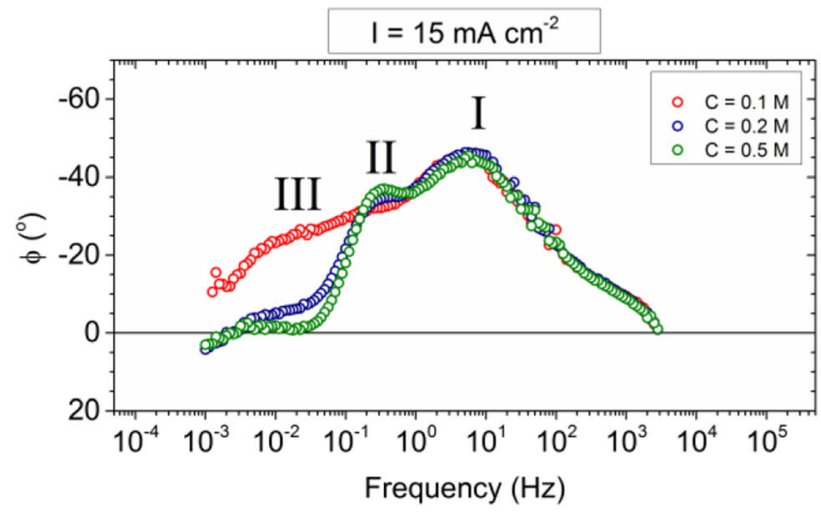

$=0.75 \mathrm{ml} \mathrm{min}^{-1}, V_{\mathrm{O} 2}=75 \mathrm{ml} \mathrm{min}^{-1}$. Insets contain the expanded view of selected spectra, presented here for clarity

63]. It thus cannot be excluded that similar inductive behavior may occur for DEFC cathodes poisoned with ethanol oxidation intermediates. Consequently, differences in the inductive portion of the spectra would reflect changes in ethanol cross-over rate with ethanol concentration (and to a smaller extent-with current density). Moreover, in some of the works on $\mathrm{H}_{2} / \mathrm{O}_{2}$ PEM FCs, inductive behavior of the cathode was also reported, associated usually with the multi-step oxygen reduction mechanism or formation of by-product species, such as platinum oxide or hydrogen peroxide [64-66]. Such reactions might also contribute to the inductive behavior observable on the DEFC impedance spectra. Thus, to better understand the 
nature of this portion of impedance spectra, further investigation is required.

\section{Influence of Anode Fuel Flow Rate}

In order to provide further information regarding the masstransfer phenomena, impedance measurements at two different ethanol flow rates $\left(V_{\mathrm{EtOH}}=0.75\right.$ and $\left.1.9 \mathrm{ml} \mathrm{min}^{-1}\right)$ were conducted. The results are presented in Figs. 4 and 5.

The spectra obtained for $0.2 \mathrm{M}$ ethanol solution in Fig. 4 show that the size of the low-frequency arc (arc III in Fig. 4) is substantially lower for the higher anode fuel flow rate $(1.9 \mathrm{ml}$ $\mathrm{min}^{-1}$ ), which is consistent with the fact that faster replenishing of ethanol used up in electrode reactions results in lower ethanol concentration gradients and, consequently, in lower mass-transfer impedance. Importantly, no changes in other parts of the impedance spectra are observed, confirming that the low-frequency arc contains a contribution from masstransfer impedance. Figure 5 shows the evolution of the spectra measured at the higher ethanol flow rate $\left(V_{\mathrm{EtOH}}=1.9 \mathrm{ml}\right.$ $\min ^{-1}$ ) as a function of current density. Faster delivery of ethanol solution to the anode allowed us to perform impedance measurements at a higher maximum current density than in the case of the lower flow rate $\left(35 \mathrm{~mA} \mathrm{~cm}^{-2}\right.$ vs. $20 \mathrm{~mA}$ $\mathrm{cm}^{-2}$ ). In Fig. 5, between 15 and $30 \mathrm{~mA} \mathrm{~cm}^{-2}$, the lowfrequency arc grows substantially with increase in current density. However, for 30 and $35 \mathrm{~mA} \mathrm{~cm}^{-2}$, the lowfrequency arcs virtually overlap, suggesting no differences in the mass-transfer impedance between those two cases. One of the possible explanations is that at a higher current density, i.e., more positive anode potential, the product distribution changes, so that the fuel is oxidized more efficiently, i.e., higher amounts of $\mathrm{CO}_{2}$ and acetic acid are formed, as compared with acetaldehyde. The latter explanation is understandable, taking into consideration that at high anode potentials creation of active oxygen species at the platinum surface is facilitated, resulting in more efficient acetic acid and carbon dioxide formation [20,37].

\section{Influence of Cell Temperature}

The current-voltage and current-power characteristics measured at different cell temperatures are presented in Fig. 6a. The measured open-circuit voltage increased when DEFC temperature increased-in particular OCVs were 448,452 and $467 \mathrm{mV}$ for 40,60 , and $80^{\circ} \mathrm{C}$ respectively. The difference between the OCV values could originate from changes in surface coverage by (by)products of ethanol oxidation and also by changes in cathode potential, due to difference in cross-over rate of ethanol and/or oxygen through the Nafion ${ }^{\circledR}$ membrane. It is well-known that platinum anode becomes poisoned in the presence of ethanol and EOR cannot proceed without depoisoning the platinum surface. The increase in OCV with temperature reflects the fact that for higher temperature, the Pt surface is depoisoned to a larger extent. However, an increase in ethanol crossover rate, which also happens when cell temperature increases, leads to a decrease of cathode potential and in turn of the OCV $[8,10]$. On the contrary, the permeation of oxygen from cathode [49] can result in depoisiong of the anode (via oxidation of strongly adsorbed surface poisons, such as adsorbed $\mathrm{CO}$ ). The observed OCV values at different cell temperatures are thus a result of superposition of numerous processes, where the abovementioned are in our opinion the most probable.

When temperature decreases, the maximum output power is significantly lowered. It can also be observed that the main voltage losses occur at relatively low current densities, and thus can be ascribed to activation voltage losses due to higher activation barrier for ethanol electro-oxidation. This is also confirmed by higher polarization resistance values for lower temperatures, as can be seen in Fig. 6b. Another observation from the current-voltage curves is that upon decreasing temperature, the mass-transfer losses become more significant.
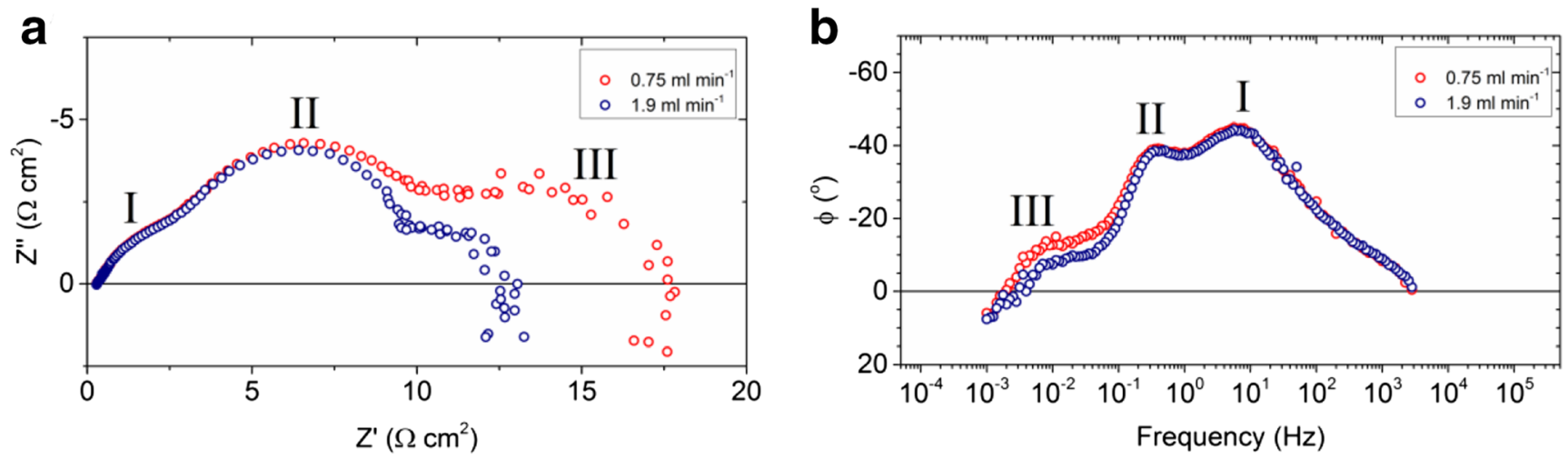

Fig. 4 Impedance spectra of DEFC with Pt:Pt anode:cathode (see text for details) fed with $0.2 \mathrm{M}$ ethanol solution at different flow rates $(0.75$ and $1.9 \mathrm{ml}$ $\min ^{-1}$ ) and oxygen as oxidizer. a) Nyquist plots and b) Bode plots. Conditions: $T=80^{\circ} \mathrm{C}, V_{\mathrm{O} 2}=75 \mathrm{ml} \mathrm{min}^{-1}, I=25 \mathrm{~mA} \mathrm{~cm}{ }^{-2}$ 

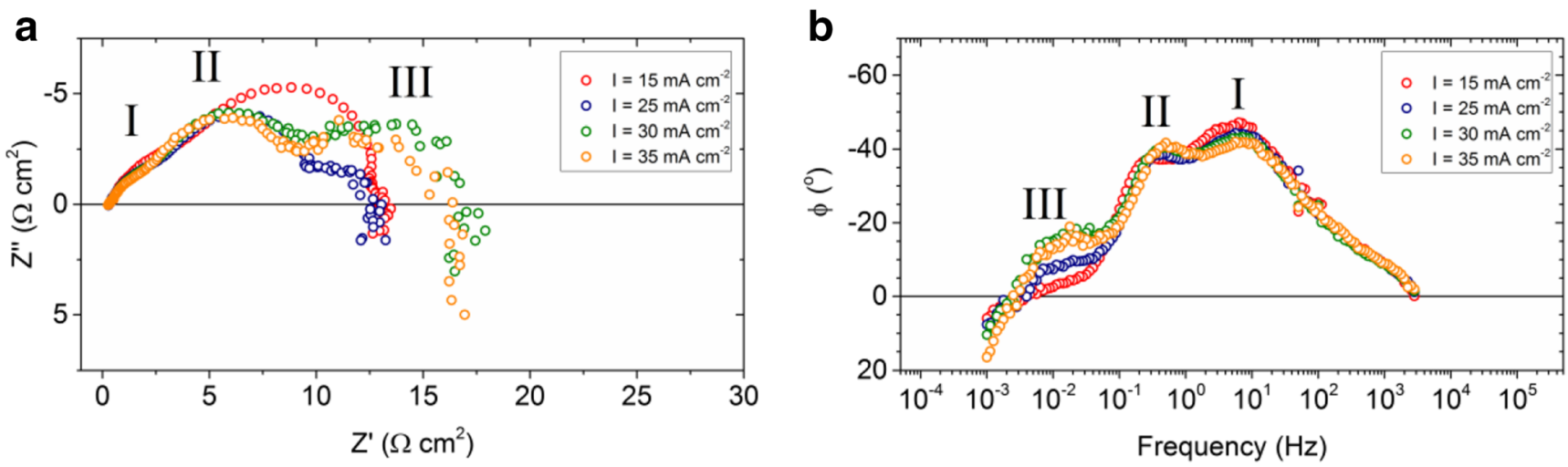

Fig. 5 Impedance spectra of DEFC with Pt:Pt anode:cathode (see text for details) fed with $0.2 \mathrm{M}$ ethanol solution and oxygen as oxidizer at different

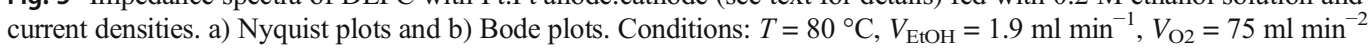

This phenomenon can be explained by decrease in ethanol diffusivity, which hinders its transport from the flow channels to the catalyst layer of the anode and to the active sites within it. Also, when temperature is increased, formation of acetic acid and $\mathrm{CO}_{2}$ is facilitated, as compared with acetaldehyde,
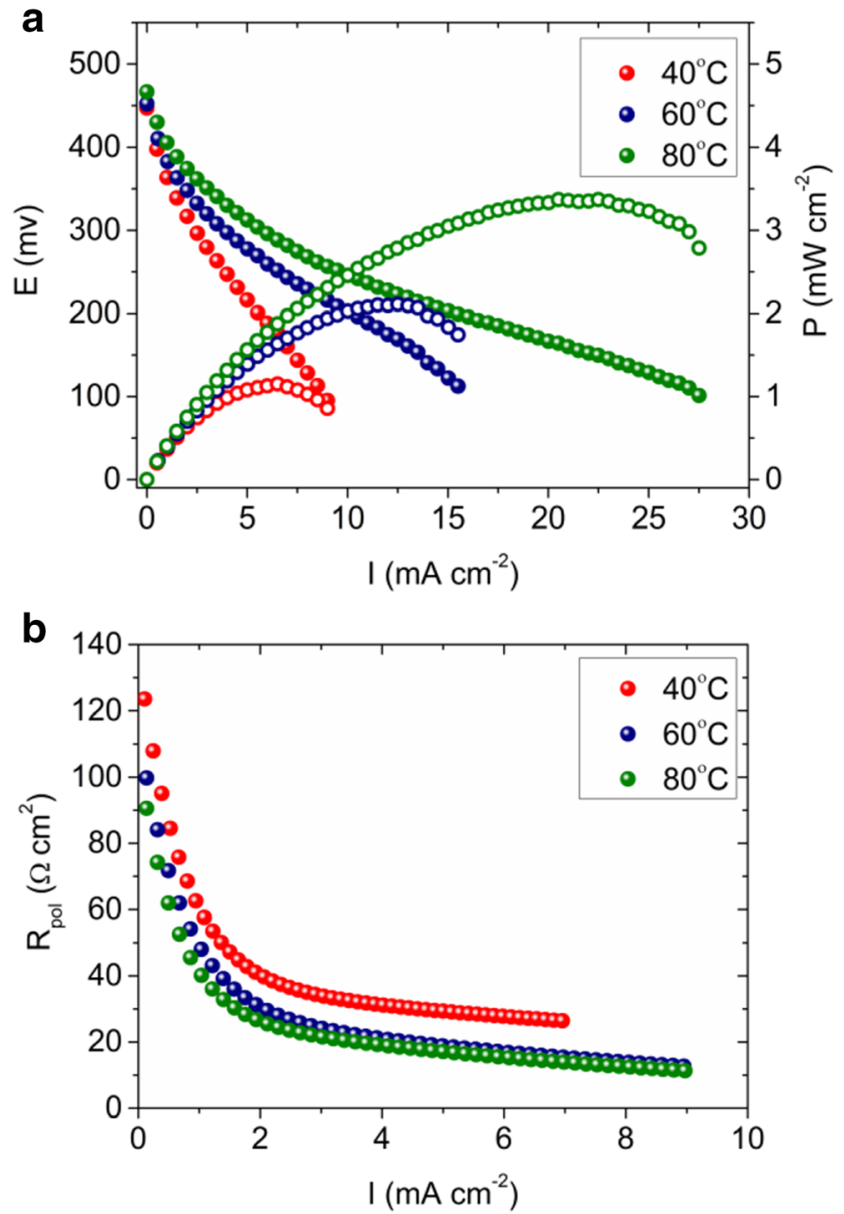

Fig. 6 a) Current-voltage (filled circles) and current-power (empty circles) characteristics. b) Polarization resistance as a function of current density for DEFC with Pt:Pt anode:cathode (see text for details) fed with $0.2 \mathrm{M}$ ethanol solution and oxygen as oxidizer at different cell tempera-

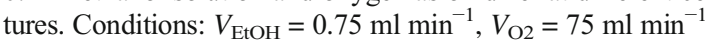

which means a more effective utilization of ethanol and in turn lowers concentration gradients near the electrode surface [37]. As stated in the previous sections, at temperature of $80^{\circ} \mathrm{C}$, voltage losses caused by anode mass-transfer resistance occur even when ethanol concentration is relatively high. A further deterioration of the mass-transfer at lower temperatures might be a major problem in practical applications of DEFC. To better understand the sources of polarization contributing to the overall voltage losses, impedance spectra at various temperatures and current densities were measured. The results are presented in Fig. 7.

The main difference between the spectra in Fig. 7 at low current density values $\left(2\right.$ and $\left.6 \mathrm{~mA} \mathrm{~cm}^{-2}\right)$ is observed in the arc corresponding to anode faradaic impedance (arc II in Fig. 7). While increasing cell temperature, the size of this arc and its relaxation time constant decrease rapidly (suggested by a shift of the phase angle maxima for arc II in the Bode plots in Fig. 7b towards higher frequencies), indicating a decrease in the anode activation voltage losses. The losses originating from anode mass-transfer resistance observed on the current-voltage curves in Fig. 6a manifest themselves as an additional low-frequency capacitive arc (arc III in Fig. 7), present only at higher current densities. As can be seen on the impedance spectra, temperature has a great impact on the mass-transfer impedance. For instance, it can be observed that for current density $I=15 \mathrm{~mA} \mathrm{~cm}^{-2}$, a relatively small decrease in cell temperature-from 80 to $60{ }^{\circ} \mathrm{C}$-results in an enormous growth of the size of the low-frequency arc (arc III in Fig. 7).

In the low-frequency part of the spectra, differences in the inductive behavior for various cell temperatures can be observed, but the direction of changes is not clear, as it depends on the current density. At $2 \mathrm{~mA} \mathrm{~cm}{ }^{-2}$, a positive phase angle on the Bode plots (Fig. 7b) appears for 40 and $60{ }^{\circ} \mathrm{C}$ at a higher frequency than for $80^{\circ} \mathrm{C}$, while at $6 \mathrm{~mA}$ $\mathrm{cm}^{-2}$, it begins at a similar frequency, but the shape of the inductive loops substantially differs. We suspect that 

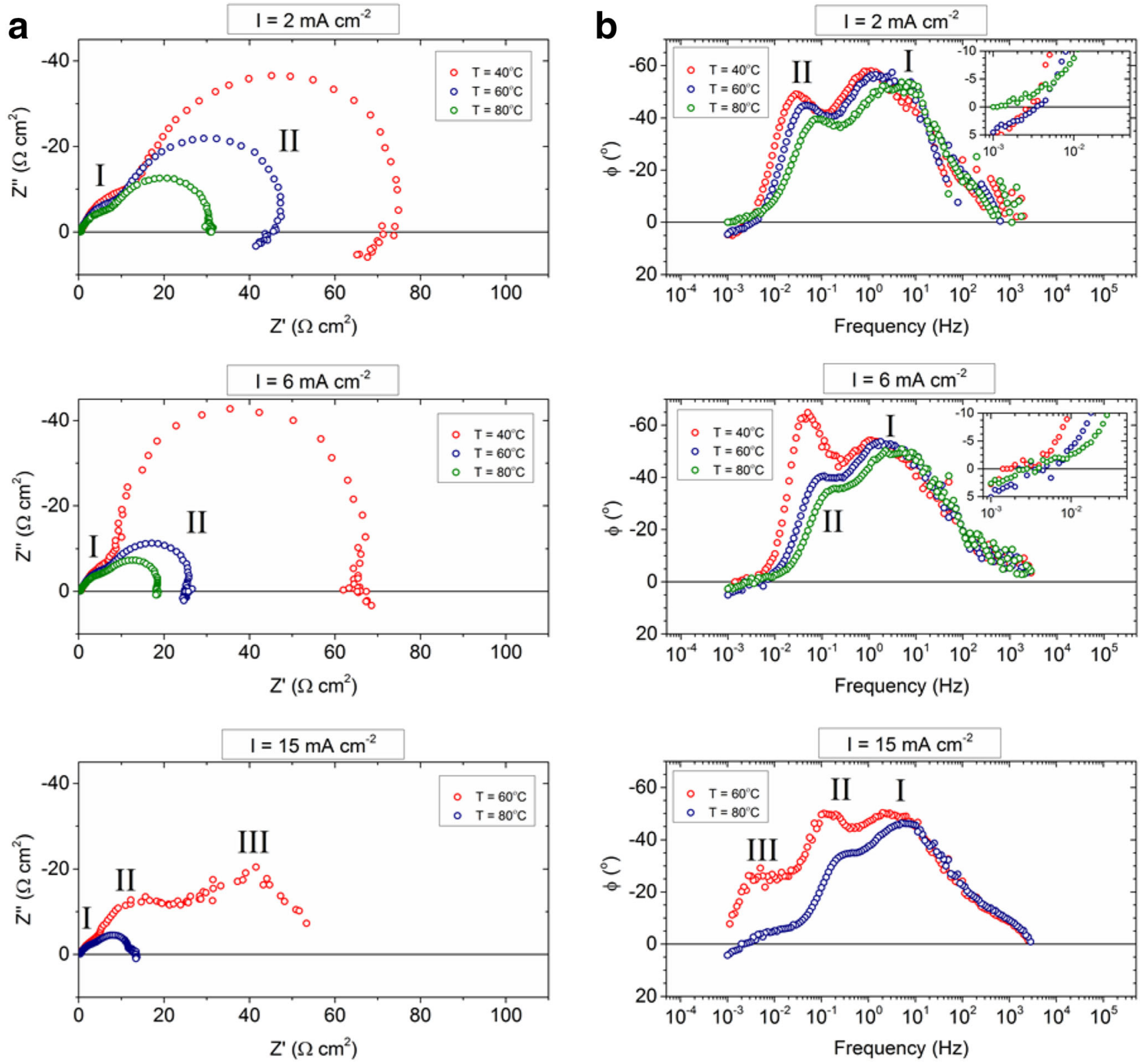

Fig. 7 Impedance spectra of DEFC with Pt:Pt anode:cathode (see text for details) fed with $0.2 \mathrm{M}$ ethanol solution and oxygen as oxidizer at different cell temperatures. a) Nyquist plots and b) Bode plots.

electrode surface coverage with different ethanol oxidation intermediates varies for different cell temperatures. It might be caused by changes of the rate determining steps of different oxidation routes with temperature. For instance, it was shown in our previous work that in a low-temperature DEFC with $\mathrm{Pt}$ electrodes electrochemical formation rate of $\mathrm{CO}_{2}$, which is a result of oxidation of $\mathrm{CO}$ intermediate, significantly increases when temperature increases, whereas for acetic acid formation, the influence of temperature is less pronounced and for acetaldehyde formation almost negligible [34].

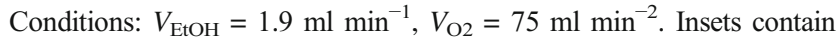
the expanded view of selected spectra, presented here for clarity

Different adsorption and desorption kinetics of the intermediate products can manifest themselves as changes in the inductive portion of the spectra. The influence of temperature and current density on ethanol cross-over rate, and in turn the cathode poisoning, may also contribute to the low-frequency inductive behavior. As can be observed from the above considerations, numerous factors influence the overall impedance of DEFC and more work is needed to better understand the processes occurring during EOR in a working DEFC. 


\section{Conclusions}

The influence of different physical parameters on a lowtemperature PEM direct ethanol fuel cell with platinum electrodes was studied using DC (galvanostatic polarization) and $\mathrm{AC}$ (electrochemical impedance spectroscopy) methods. The registered current-voltage and currentpower characteristics allowed us to assess cell performance in a wide range of current density loads, while the impedance spectra provided insight into distinct contributions to the overall cell polarization. The anode faradaic impedance was shown to be a function of current density and cell temperature, but was not significantly influenced by ethanol concentration. Impact of the cathode faradaic impedance on the cell performance was not evident from the obtained data and assumed low in comparison with the anode impedance. An important finding in this work is the presence of a significant anode masstransfer resistance even at excess of ethanol, especially at cell temperatures lower than $80{ }^{\circ} \mathrm{C}$. Low selectivity towards complete ethanol oxidation, low rate of ethanol diffusion to the active anode sites, and parasitic processes of ethanol and oxygen cross-over were proposed as possible reasons. The inductive behavior observed in the low-frequency region could be attributed to slow processes of adsorption and desorption of reaction intermediates on the surface of electrodes. Changes in this part of the spectrum upon varying cell parameters might correspond to changes in ethanol electro-oxidation mechanism. An exact explanation of these differences is a big challenge, considering large relaxation time constants of the observed inductive phenomena, especially at low current densities. Even very low perturbation frequencies applied in this study (down to $1 \mathrm{mHz}$ ) did not reveal the full shape of the inductive loops. Moreover, for proper interpretation of the low-frequency part of the spectra, for certain conditions (low ethanol concentration, high current, low temperature), overlapping of the inductive phenomena with mass-transfer impedance must be taken into account. Further studies are also needed to determine the exact nature of the high-frequency arc and elucidate the contribution from the cathode reactions to the overall cell impedance. In order to describe the impedance spectra quantitatively, an equivalent circuit model needs to be developed, which will be the subject of our future research.

Funding Information This project was funded from the Polish National Science Centre budget based on decision number DEC-2013/09/B/ST4/ 00099. The study was carried out at the Biological and Chemical Research Centre, University of Warsaw, established within the project co-financed by European Union from the European Regional Development Fund under the Operational Programme Innovative Economy, 2007-2013.
Open Access This article is distributed under the terms of the Creative Commons Attribution 4.0 International License (http:// creativecommons.org/licenses/by/4.0/), which permits unrestricted use, distribution, and reproduction in any medium, provided you give appropriate credit to the original author(s) and the source, provide a link to the Creative Commons license, and indicate if changes were made.

\section{References}

1. M. Winter, R.J. Brodd, Chem Rev 104, 4245-4269 (2004)

2. S.P.S. Badwal, S. Giddey, A. Kulkarni, J. Goel, S. Basu, Appl Energ 145, 80-103 (2015)

3. C. Lamy, E.M. Belgsir, J.M. Leger, J Appl Electrochem 31, 799809 (2001)

4. L. An, T.S. Zhao, Y.S. Li, Renew Sust Energ Rev 50, 1462-1468 (2015)

5. U.B. Demirci, J Power Sources 169, 239-246 (2007)

6. B. Gavriel, R. Sharabi, L. Elbaz, ChemSusChem 10, 3069-3074 (2017)

7. Q. Li, G. Wu, C.M. Johnston, P. Zelenay, Electrocatalysis 5, 310 317 (2014)

8. G.C. Li, P.G. Pickup, J Power Sources 161, 256-263 (2006)

9. H. Hitmi, E.M. Belgsir, J.M. Leger, C. Lamy, R.O. Lezna, Electrochim Acta 39, 407-415 (1994)

10. S. Song, W. Zhou, J. Tian, R. Cai, G. Sun, Q. Xin, S. Kontou, P. Tsiakaras, J Power Sources 145, 266-271 (2005)

11. G. Andreadis, P. Tsiakaras, Chem Eng Sci 61, 7497-7508 (2006)

12. R. Borup, J. Meyers, B. Pivovar, Y.S. Kim, R. Mukundan, N. Garland, D. Myers, M. Wilson, F. Garzon, D. Wood, P. Zelenay, K. More, K. Stroh, T. Zawodzinski, J. Boncella, J.E. McGrath, M. Inaba, K. Miyatake, M. Hori, K. Ota, Z. Ogumi, S. Miyata, A. Nishikata, Z. Siroma, Y. Uchimoto, K. Yasuda, K.I. Kimijima, N. Iwashita, Chem Rev 107, 3904-3951 (2007)

13. Z. Zakaria, S.K. Kamarudin, S.N. Timmiati, Appl Energ 163, 334 342 (2016)

14. L. Dubau, L. Castanheira, F. Maillard, M. Chatenet, O. Lottin, G. Maranzana, J. Dillet, A. Lamibrac, J.C. Perrin, E. Moukheiber, A. ElKaddouri, G. De Moor, C. Bas, L. Flandin, N. Caque, Wires Energy Environ 3, 540-560 (2014)

15. T. Iwasita, B. Rasch, E. Cattaneo, W. Vielstich, Electrochim Acta 34, 1073-1079 (1989)

16. A. Brouzgou, A. Podias, P. Tsiakaras, J Appl Electrochem 43, 119 $136(\mathbf{2 0 1 3})$

17. F.C. Simoes, D.M. dos Anjos, F. Vigier, J.M. Leger, F. Hahn, C. Coutanceau, E.R. Gonzalez, G. Tremiliosi-Filho, A.R. de Andrade, P. Olivi, K.B. Kokoh, J Power Sources 167, 1-10 (2007)

18. E. Antolini, E.R. Gonzalez, Catal Today 160, 28-38 (2011)

19. A. Jablonski, A. Lewera, Appl Catal B-Environ 115, 25-30 (2012)

20. N. Nakagawa, Y. Kaneda, M. Wagatsuma, T. Tsujiguchi, J Power Sources 199, 103-109 (2012)

21. R.B. Kutz, B. Braunschweig, P. Mukherjee, R.L. Behrens, D.D. Dlott, A. Wieckowski, J Catal 278, 181-188 (2011)

22. M. Heinen, Z. Jusys, R.J. Behm, J Phys Chem C 114, 9850-9864 (2010)

23. A. Kowal, M. Li, M. Shao, K. Sasaki, M.B. Vukmirovic, J. Zhang, N.S. Marinkovic, P. Liu, A.I. Frenkel, R.R. Adzic, Nat Mater 8 , 325-330 (2009)

24. M. Li, A. Kowal, K. Sasaki, N. Marinkovic, D. Su, E. Korach, P. Liu, R.R. Adzic, Electrochim Acta 55, 4331-4338 (2010)

25. E.A. de Souza, M.J. Giz, G.A. Camara, E. Antolini, R.R. Passos, Electrochim Acta 147, 483-489 (2014)

26. N. Erini, R. Loukrakpam, V. Petkov, E.A. Baranova, R.Z. Yang, D. Teschner, Y.H. Huang, S.R. Brankovic, P. Strasser, Acs Catal 4, 1859-1867 (2014) 
27. G.X. Yang, L.M. Namin, N.A. Deskins, X.W. Teng, J Catal 353, 335-348 (2017)

28. G.A.B. Mello, M.J.S. Farias, M.J. Giz, G.A. Camara, Electrochem Commun 48, 160-163 (2014)

29. M. Li, W.P. Zhou, N.S. Marinkovic, K. Sasaki, R.R. Adzic, Electrochim Acta 104, 454-461 (2013)

30. S. Beyhan, J.M. Leger, F. Kadirgan, Appl Catal B-Environ 144, 6674 (2014)

31. P.T. Mai, M. Chiku, E. Higuchi, H. Inoue, J Electrochem Soc 164, F1011-F1013 (2017)

32. G.X. Yang, A.I. Frenkel, D. Su, X.W. Teng, Chemcatchem 8, 28762880 (2016)

33. L.A. Soares, C. Morais, T.W. Napporn, K.B. Kokoh, P. Olivi, J Power Sources 315, 47-55 (2016)

34. E.V. Spinace, R.R. Dias, M. Brandalise, M. Linardi, A.O. Neto, Ionics 16, 91-95 (2010)

35. J.C. Castro, R.M. Antoniassi, R.R. Dias, M. Linardi, E.V. Spinace, A.O. Neto, Ionics 18, 781-786 (2012)

36. S. Beyhan, C. Coutanceau, J.M. Leger, T.W. Napporn, F. Kadirgan, Int J Hydrogen Energ 38, 6830-6841 (2013)

37. J. Seweryn, A. Lewera, Appl Catal B-Environ 144, 129-134 (2014)

38. P. Piela, R. Fields, P. Zelenay, J Electrochem Soc 153, A1902A1913 (2006)

39. S.M.R. Niya, M. Hoorfar, J Power Sources 240, 281-293 (2013)

40. S. Uhm, S.T. Chung, J. Lee, J Power Sources 178, $34-43$ (2008)

41. P. Ekdharmasuit, A. Therdthianwong, S. Therdthianwong, Int $J$ Hydrogen Energ 39, 1775-1782 (2014)

42. S.C. Zignani, V. Baglio, J.J. Linares, G. Monforte, E.R. Gonzalez, A.S. Arico, Int J Hydrogen Energ 38, 11576-11582 (2013)

43. D.A. Moreno-Jimenez, D.E. Pacheco-Catalan, L.C. Ordonez, Int J Electrochem Sc 10, 8808-8822 (2015)

44. J.F. Wu, X.Z. Yuan, H.J. Wang, M. Blanco, J.J. Martin, J.J. Zhang, Int J Hydrogen Energ 33, 1735-1746 (2008)

45. T. Lopes, E. Antolini, F. Colmati, E.R. Gonzalez, J Power Sources 164, 111-114 (2007)

46. T. Lopes, E. Antolini, E.R. Gonzalez, Int J Hydrogen Energ 33, 5563-5570 (2008)
47. C.V. Rao, B. Viswanathan, Electrochim Acta 55, 3002-3007 (2010)

48. G.A. Camara, T. Iwasita, J Electroanal Chem 578, 315-321 (2005)

49. A. Jablonski, P.J. Kulesza, A. Lewera, J Power Sources 196, 4714 4718 (2011)

50. J.T. Mueller, P.M. Urban, J Power Sources 75, 139-143 (1998)

51. S.H. Yang, C.Y. Chen, W.J. Wang, J Power Sources 195, 2319 2330 (2010)

52. S.H. Yang, C.Y. Chen, W.J. Wang, J Power Sources 195, 35363545 (2010)

53. S.Y. Ahn, Y.C. Lee, H.Y. Ha, S.A. Hong, I.H. Oh, Electrochim Acta 50, 673-676 (2004)

54. S.B. Wang, S. Jing, Z.M. Mao, X.F. Xie, Int J Hydrogen Energ 41, 16247-16253 (2016)

55. C. Desilets, A. Lasia, Electrochim Acta 78, 286-293 (2012)

56. C.N. Cao, Electrochim Acta 35, 831-836 (1990)

57. C.N. Cao, Electrochim Acta 35, 837-844 (1990)

58. N. Wagner, E. Gulzow, J Power Sources 127, 341-347 (2004)

59. A. Lasia, Electrochemical impedance spectroscopy and its applications (Springer, New York, 2014)

60. J.S. Kim, S.I. Pyun, J Solid State Electr 15, 2447-2452 (2011)

61. A. Lasia, J Electroanal Chem 500, 30-35 (2001)

62. M. Inoue, T. Iwasaki, M. Umeda, Electrochemistry 79, 329-333 (2011)

63. C.Y. Du, T.S. Zhao, W.W. Yang, Electrochim Acta 52, 5266-5271 (2007)

64. R.K. Singh, R. Devivaraprasad, T. Kar, A. Chakraborty, M. Neergat, J Electrochem Soc 162, F489-F498 (2015)

65. S.K. Roy, M.E. Orazem, B. Tribollet, J Electrochem Soc 154, B1378-B1388 (2007)

66. J.J. Giner-Sanz, E.M. Ortega, V. Perez-Herranz, J Power Sources 379, 328-337 (2018)

Publisher's Note Springer Nature remains neutral with regard to jurisdictional claims in published maps and institutional affiliations. 